\title{
Sustentabilidade do processo construtivo habitacional vernacular na aldeia Indígena Itapoã Tupinambá de Olivença/BA/Brasil
}

Este artigo apresenta os resultados da Pesquisa intitulada Arquitetura Vernacular de edificações habitacionais como expressão ambiental e cultural no Litoral Sul do Estado da Bahia, Brasil, que objetivou identificar, catalogar e analisar habitações construídas em Comunidades Tradicionais entre os municípios de Itacaré e Una. Partiu-se da hipótese de que o processo construtivo vernacular em Comunidades Tradicionais vem sendo gradativamente substituído por tecnologias construtivas e materiais convencionais, tais como: concreto, argamassa de cimento e tijolos cerâmicos. A Aldeia Indígena Itapoã Tupinambá de Olivença foi escolhida para a coleta das informações. As técnicas de Pesquisa utilizadas foram o registro em diário de campo e um roteiro de entrevista semiestruturada aplicado a um grupo focal, constituído por anciãos da Aldeia, responsável por transmitir o conhecimento acerca do processo construtivo das habitações para a Comunidade. Tanto as descrições em diário de campo quanto as respostas da entrevista foram analisadas considerando: 1 estratégias arquitetônicas bioclimáticas intuitivas utilizadas no processo construtivo das habitações, 2 extração e uso dos Recursos Naturais locais e 3 a relação meio ambiente e Comunidade. Os resultados mostraram que: a) a tipologia vernacular predominante na área de abrangência da Pesquisa e na Aldeia Indígena estudada é o Pau-a-Pique; b) o dimensionamento das habitações, o cálculo dos materiais a serem extraídos da Mata local, rituais para extração dos materiais são definidos e orientados pelo grupo de anciãos da Aldeia, c) o processo coletivo de construção das habitações fortalecem os laços sociais dentro da Comunidade e d) apesar da importância ambiental e cultural do processo vernacular de construção, há materiais convencionais sendo utilizados para substituir as tramas de madeira e argamassa de argila, água, areia e fibras que compõem as paredes das habitações, o que corrobora a hipótese da Pesquisa.

\section{Sustainability of the vernacular dwelling's construction process in the indigenous village Itapoã Tupinambá Of Olivença/BA/Brazil}

\begin{abstract}
This article presents the results of the research entitled Vernacular Architecture of dwellings as an environmental and cultural expression in the Southern Coast of Bahia State, Brazil, which aimed to identify, catalog and analyze dwellings built in Traditional Communities between the municipalities of Itacaré and Una. It was hypothesized that the vernacular constructive process in Traditional Communities has been gradually replaced by constructive technologies and conventional materials, such as concrete, cement mortar and ceramic bricks. The Indigenous Village Itapoã Tupinambá of Olivença was chosen for data collection. The research techniques used were the field journal and a semi-structured interview script applied to a focal group, made up of elders of the Village, responsible for transmitting the knowledge about the constructive process of the dwellings for the community. Both field journal descriptions and interview responses were analyzed considering: 1 intuitive bioclimatic architectural strategies used in the dwellings constructive process, 2 extraction and use of local Natural Resources, and 3 the relationship between environment and the community. The results showed that: a) the predominant vernacular typology in the research area and in the Indigenous Village studied is the Pau-a-Pique; b) the sizing of the dwellings, the calculation of the materials to be extracted from the local Forest, rituals for extraction of the materials and all the construction process is taught and coordinated by the group of the Village elders, c) the collective process of the dwellings construction strengthen the community social ties, and d) despite of the cultural and environmental importance of the vernacular construction process, there are conventional materials being used to replace the wood and mortar plots of clay, water, sand and fibers that make up the walls of the dwellings, which corroborates the research hypothesis.
\end{abstract}

Keywords: Vernacular Architecture; Sustainability; Traditional Brazilian Communities.

Topic: Uso Sustentável da Biodiversidade

Reviewed anonymously in the process of blind peer.
Received: 02/12/2018

Approved: 26/01/2019
Silvia Kimo Costa (iD)

Universidade Federal do Sul da Bahia, Brasil

http://lattes.cnpq.br/9149115967689036

http://orcid.org/0000-0002-2191-3365

skcosta@ufsb.edu.br
Referencing this:

COSTA, S. K.. Sustentabilidade do processo construtivo habitacional vernacular na aldeia Indígena Itapoã Tupinambá de Olivença/BA/Brasil. Revista Ibero Americana de Ciências Ambientais, v.10, n.1, p.64-76, 2019. DOI: http://doi.org/10.6008/CBPC2179$\underline{6858.2019 .001 .0006}$

DOI: 10.6008/CBPC2179-6858.2019.001.0006 


\section{INTRODUÇÃO}

A arquitetura vernacular depende de condições geográficas, climáticas, aspectos socioculturais específicos e, por esse motivo, sua manifestação ocorre de maneira singular em diferentes partes do mundo (ALVES, 2017; WEBER et al., 2014; OLIVER, 2006). No Brasil, a arquitetura vernacular também é conhecida como arquitetura popular, pois a construção das edificações ocorre de maneira coletiva pela população das camadas intermediárias da sociedade (WEIMER, 2005). Em Comunidades Tradicionais brasileiras, tais como Aldeias Indígenas, o processo coletivo de construção das edificações é extremamente importante para a manutenção cultural da Comunidade e envolve rituais de celebração.

O Decreto 6.040 (BRASIL, 2007) reconhece as Comunidades Tradicionais brasileiras como grupos culturalmente diferenciados, que possuem meios próprios de organização social, uso da terra e dos recursos naturais. Nessas comunidades a reprodução cultural, social, religiosa, ancestral, econômica e o processo construtivo coletivo das edificações vernaculares são compartilhados através das gerações. Considerando o exposto, este artigo apresenta os resultados da Pesquisa intitulada - Arquitetura vernacular de edificações habitacionais como expressão ambiental e cultural no Litoral Sul do Estado da Bahia, Brasil, que objetivou identificar, catalogar e analisar habitações em Comunidades Tradicionais entre os municípios de Itacaré e Una.

Partiu-se da hipótese de que o processo construtivo vernacular, que necessariamente envolve a extração e utilização de materiais oriundos dos Recursos Naturais locais assim como estratégias arquitetônicas bioclimáticas intuitivas, vêm sendo substituídos por tecnologias construtivas convencionais e materiais tais como o concreto, argamassa de cimento e tijolos cerâmicos. A substituição do processo construtivo vernacular e dos materiais naturais por tecnologias construtivas convencionais e materiais industrializados não só interfere na preservação do habitus cultural das Comunidades Tradicionais como também potencializa o impacto ambiental advindo da construção civil, uma vez que no processo de construção vernacular a Comunidade extrai dos Recursos Naturais apenas o necessário para sua subsistência.

Trata-se então, de uma Pesquisa Descritiva acerca do processo construtivo das habitações vernaculares demonstrando sua importância para a sustentabilidade ambiental local no que tange aos aspectos bioclimáticos, uso dos Recursos Naturais e preservação cultural. Para coleta das informações foram utilizadas a observação participante, registrada em diário de campo, e a entrevista semiestruturada aplicada aos principais construtores responsáveis por compartilhar, com a Comunidade, o conhecimento referente ao processo construtivo vernacular das habitações.

A Aldeia Indígena Itapoã Tupinambá, localizada no Distrito de Olivença pertencente ao município de Ilhéus, Bahia, foi escolhida para coleta das informações por ser a Comunidade Tradicional que apresentou a maior quantidade de habitações identificadas como vernaculares na área de abrangência da Pesquisa. 0 estudo considerou a interrelação entre os seguintes temas norteadores - arquitetura vernacular, estratégias arquitetônicas bioclimáticas e eficiência energética. 
Segundo Guy et al. (2001), a arquitetura vernacular está relacionada à vertente de sustentabilidade arquitetônica conceitual denominada Ecocultural. Que enfatiza o senso de identidade envolvendo uma relação de subjetividade individual com a Natureza - uma consciência ecológica - e há uma preocupação em preservar o significado do processo de construção vernacular. A arquitetura vernacular, do ponto de vista da identidade cultural, é uma representação social ligada a valores culturais e sistemas de crenças; representa um elo com o lugar e patrimônio histórico (PLEVOETS et al., 2018; HĂRMĂNESCU et al., 2016; CORREA et al. 2014; ASQUITH et al., 2005).

Edificações vernaculares são mais comuns em territórios rurais do que urbanos. Segundo Donovan et al. (2014), as condições ambientais do território rural (em todo o mundo) possibilitam construções com as características da arquitetura vernacular, devido à maior disponibilidade de materiais naturais locais. No Brasil, a arquitetura vernacular ou popular predomina no território rural, e as técnicas de construção, materiais utilizados, aspectos do design, são influenciados principalmente pelas culturas indígena e africana (LIMA JUNIOR, 2007).

Do ponto de vista ambiental, a arquitetura vernacular é um exemplo de sustentabilidade não só em virtude do uso de materiais naturais locais no processo construtivo, minimizando o impacto ambiental da construção (HAMARD et al., 2016; MOREL et al., 2001), mas também em função do design da edificação baseado, intuitivamente, em estratégias arquitetônicas bioclimáticas (PHILOKYPROU et al., 2017).

As estratégias arquitetônicas bioclimáticas visam manter o conforto ambiental interno em uma edificação através de aspectos climáticos de interação energética com o ambiente externo (MANZANOAGUGLIARO et al., 2015). De acordo com Philokyprou et al. (2012), o design bioclimático está relacionado à aplicação de estratégias referentes ao aquecimento e resfriamento passivo, aprimorando as condições microclimáticas dos ambientes e à exploração da iluminação e ventilação naturais.

As estratégias bioclimáticas são intrínsecas à arquitetura vernacular porque o clima define o design (BECALLI et al., 2018), além dos aspectos culturais e sociais. Quanto mais severas as condições climáticas, mais limitadas serão as soluções arquitetônicas para o edifício (COCH, 1998). No que se refere à Eficiência Energética, um edifício energeticamente eficiente proporciona condições de conforto interno com menor consumo de energia (CORBELLA et al., 2011). Estratégias arquitetônicas bioclimáticas influenciam a eficiência energética do edifício (PREVITALI et al., 2016).

Kibert (2013) e Duran (2011) destacam algumas das estratégias arquitetônicas bioclimáticas passivas e ativas que permitem a eficiência energética das edificações: a) Incidência solar, direção do vento e orografia para termorregulação de ambientes internos. b) Utilização de materiais com alta massa térmica e capacidade de expansão. c) O telhado verde e a fachada verde podem ser usados como sistemas de controle térmico que purifica o ar - refresca os ambientes internos dos edifícios durante o dia e regula a mudança de temperatura à noite. d) Uso de envelopamento de fachada para regulação de temperatura durante a mudança climática. e) Soluções tecnológicas utilizadas para produzir energia através de fontes de energia renováveis, tais como: painéis fotovoltaicos, energia solar, eólica, energia hidroelétrica, geotérmica e 
biomassa. f) Sistema automático de aquecimento ou resfriamento para ajustar a temperatura interna do prédio de acordo com as mudanças externas de temperatura.

Chandel et al. (2016); Zhai et al. (2010) afirmam que o consumo de energia em uma habitação vernacular varia de acordo com o design da mesma, depende da iluminação e ventilação natural, materiais de vedação (paredes), materiais de revestimento, tamanho das janelas, estratégias de sombreamento e uso da terra. Ou seja, a eficiência energética das habitações vernaculares depende das estratégias arquitetônicas bioclimáticas usadas no processo de design e construção.

Considerando a interrelação entre os temas norteadores da Pesquisa e as técnicas para coleta das informações, foi possível descrever o processo construtivo coletivo das habitações vernaculares na Aldeia Indígena Itapoã Tupinambá de Olivença considerando 1 estratégias arquitetônicas bioclimáticas intuitivas utilizadas no processo construtivo das habitações e 2 a relação meio ambiente e Comunidade.

\section{RESISÃO TEÓRICA}

\section{Contexto da pesquisa}

A arquitetura vernacular brasileira, predominante no território rural, apresenta tipologias de edificações que variam de acordo com as condições climáticas das regiões do país (Tabela 1).

Tabela 1: Clima brasileiro e características da arquitetura vernacular no território rural em todo o país.

\begin{tabular}{|c|c|c|c|}
\hline $\begin{array}{c}\text { Ranking } \\
\text { Climático de } \\
\text { Strahler }\end{array}$ & Descrição geral do clima & Localidade no Brasil & $\begin{array}{c}\text { Arquitetura vernacular predominante no território } \\
\text { rural brasileiro }\end{array}$ \\
\hline $\begin{array}{l}\text { Equatorial } \\
\text { úmido }\end{array}$ & $\begin{array}{l}\text { Caracterizada pela ação direta das massas de ar } \\
\text { continentais e equatoriais de ar quente e úmido; } \\
\text { altas temperaturas médias variando de } 25^{\circ} \mathrm{C} \text { a } 27 \\
{ }^{\circ} \mathrm{C} \text {; precipitação ao longo do ano e redução da } \\
\text { amplitude térmica. }\end{array}$ & $\begin{array}{l}\text { Amazônia; Norte do Mato Grosso e } \\
\text { oeste do Maranhão. }\end{array}$ & $\begin{array}{l}\text { Palafitas: sustentação vertical da estrutura da } \\
\text { habitação, feita de madeira, para escapar da maré ou } \\
\text { cheia de rios. } \\
\text { Flutuante: habitações construídas sobre um sistema } \\
\text { de boias que permite que as mesmas se adequem ao } \\
\text { nível das águas dos rios. } \\
\text { Adobe: tijolo feito de argila, silte e areia que serve } \\
\text { como estrutura de construção e parede. }\end{array}$ \\
\hline $\begin{array}{l}\text { Tropical seco e } \\
\text { úmido }\end{array}$ & $\begin{array}{l}\text { Caracterizado por temperaturas elevadas variando } \\
\text { de } 18^{\circ} \mathrm{C} \text { a } 28^{\circ} \mathrm{C} \text {, com intervalo térmico de } 5^{\circ} \mathrm{C} \text { a } 7 \\
{ }^{\circ} \mathrm{C} \text {, e estações bem definidas (verão chuvoso e } \\
\text { inverno seco). }\end{array}$ & $\begin{array}{l}\text { Região central do Brasil; porção } \\
\text { leste do Maranhão; Piauí; oeste da } \\
\text { Bahia e Minas Gerais; Rio de } \\
\text { Janeiro; Espírito Santo e extremo } \\
\text { norte do país. }\end{array}$ & $\begin{array}{l}\text { Pau-a-Pique: processo construtivo que consiste em } \\
\text { montar uma estrutura feita de tramas de ripas ou } \\
\text { toras finas de madeira e/ ou bambu, amarradas com } \\
\text { cipó e preenchidas com argamassa de argila, areia, } \\
\text { água e fibras naturais. } \\
\text { Adobe }\end{array}$ \\
\hline $\begin{array}{l}\text { Tropical seco } \\
\text { (semi-árido) }\end{array}$ & $\begin{array}{l}\text { Caracterizada por altas temperaturas (média de } 27 \\
{ }^{\circ} \mathrm{C} \text { ), chuvas escassas e mal distribuídas, cerca de } \\
700 \text { milímetros anuais. }\end{array}$ & $\begin{array}{l}\text { Interior do Nordeste (conhecido } \\
\text { como "Polígono das Secas"), e vales } \\
\text { médio e baixo do Rio São Francisco. }\end{array}$ & Pau-a-pique \\
\hline Litoral úmido & $\begin{array}{l}\text { Caracterizada pela ação direta da massa tropical } \\
\text { do Atlântico, chuvas intensas e temperatura } \\
\text { variando de } 18^{\circ} \mathrm{C} \text { a } 26^{\circ} \mathrm{C} \text {. }\end{array}$ & $\begin{array}{l}\text { Faixa Costeira Rio Grande do Norte } \\
\text { ao Paraná. }\end{array}$ & $\begin{array}{l}\text { Arquitetura vernacular praieira: caracterizada pela } \\
\text { predominância do pau-a-pique e por edificações } \\
\text { construídas em estrutura de madeira com paredes de } \\
\text { palha trançada e telhado coberto por piaçava. }\end{array}$ \\
\hline $\begin{array}{l}\text { Subtropical } \\
\text { úmido }\end{array}$ & $\begin{array}{l}\text { Caracterizada pela massa polar Atlântica. Verão } \\
\left.\text { quente (temperatura pode exceder } 30^{\circ} \mathrm{C}\right) \text {. Inverno } \\
\text { frio com as temperaturas mais baixas do país, } \\
\text { abaixo de } 0^{\circ} \mathrm{C} \text {. }\end{array}$ & $\begin{array}{l}\text { Sul de São Paulo; Paraná; Santa } \\
\text { Catarina e Rio Grande do Sul. }\end{array}$ & $\begin{array}{l}\text { Enxamiel: técnica construtiva vernacular caracterizada } \\
\text { por paredes montadas com hastes de madeira } \\
\text { encaixadas nas posições horizontal, vertical e } \\
\text { inclinada, cujos espaços entre essas hastes são } \\
\text { preenchidos por tijolos ou pedras. } \\
\text { Tábuas e Mata - Juntas: estrutura que interliga os } \\
\text { pilares à estrutura de madeira do telhado è estrutura } \\
\text { horizontal (pisos e revestimentos) e vedações verticais } \\
\text { (paredes). }\end{array}$ \\
\hline
\end{tabular}

Fonte: Santos et al. (2017) e Danni-Oliveira (2007).

O clima Litoral Úmido predomina na área de abrangência da Pesquisa (Litoral Sul da Bahia). Segundo Santos et al. (2009), essa região é caracterizada por microclima quente, úmido e subúmido, com 
temperaturas anuais variando entre $20^{\circ}$ e $30^{\circ} \mathrm{C}$. A amplitude térmica pode ser maior ou menor na faixa costeira. Quanto às chuvas, especificamente na área entre os municípios de Itacaré e Una, as taxas anuais de precipitação podem chegar até $2.400 \mathrm{~mm}$. As chuvas são regulares ao longo do ano e mais abundantes nos meses de maio a agosto.

A tipologia de edificação habitacional vernacular predominante nessa área é a arquitetura vernacular praieira (Lima Junior, 2007), caracterizada pelo Pau-a-Pique e por edificações construídas em estrutura de madeira com paredes de palha trançada e telhado coberto por piaçava (Attalea funifera Mart). O Pau-a-Pique é um processo construtivo que consiste em montar uma estrutura feita de tramas de ripas ou toras finas de madeira e/ ou bambu, amarradas com cipó e preenchidas com argamassa de argila, areia, água e fibras naturais.

Na Aldeia Indígena Itapoã Tupinambá de Olivença foi identificada a predominância do Pau-a-Pique como tipologia construtiva. A Aldeia está localizada em um Distrito do município de Ilhéus, Bahia (nas coordenadas $15^{\circ} 00$ '06" sul 3900' 04" oeste). As visitas à Aldeia, para coleta das informações, ocorreram entre os meses de março e agosto de 2018. As técnicas de pesquisa utilizadas foram a observação participante com registros em diário de campo, e roteiro de entrevista semiestruturada aplicada a um grupo focal constituído por 10 construtores vernaculares anciãos (homens e mulheres), responsáveis pelo compartilhamento do processo construtivo das habitações com as novas gerações.

\section{METODOLOGIA}

Para identificar, catalogar e analisar as habitações vernaculares em Comunidades Tradicionais entre os municípios de Itacaré e Una (localizados no Litoral Sul da Bahia), foram realizadas as seguintes etapas: Etapa 1 Revisão Sistemática de Literatura abordando os aspectos conceituais, construtivos e culturais da arquitetura vernacular brasileira. Os resultados foram publicados no artigo intitulado: Vernacular or Popular Brazilian Architecture: approaches, building aspects and cultural identity (SANTOS et al., 2017); Etapa 2 Mapeamento das habitações vernaculares entre os municípios de Itacaré e Una, Bahia. As viagens para mapeamento foram realizadas entre agosto de 2017 e fevereiro de 2018. A maior concentração de características vernaculares construtivas em habitações foi encontrada na Aldeia Indígena Itapoã Tupinambá de Olivença. Foram catalogadas cerca de 50 habitações coletivamente construídas em Pau-a-Pique na localidade; Etapa 3 Procedimentos para aprovação do Protocolo de Pesquisa pelo Comitê Brasileiro de Ética em Pesquisa. Os procedimentos foram realizados conforme a Resolução CNS 196/1996, Resolução CNS 304/2000, e Resolução CNS 510/2016. O Protocolo de Pesquisa permitiu a coleta das informações na Aldeia Indígena Itapoã Tupinambá de Olivença a partir de 20 de março de 2018. CAAE Processo no: 73793217.4.0000.5526, Parecer no 2.552.460/ 2018; Etapa 4 Pesquisa de Campo; Etapa 4.1 Diário de campo (esboços das habitações e relatório fotográfico). O diário de campo objetivou registrar as estratégias arquitetônicas bioclimáticas intuitivamente utilizadas, pela comunidade, na construção das habitações. Os registros foram realizados entre os meses de abril e maio de 2018. Foram determinadas as seguintes variáveis, considerando como referência para análise a publicação "Built to meet needs - cultural issues in 
Vernacular Architecture" by Oliver (2006): a) Posição da habitação em relação à incidência solar e direção do vento; b) Design da planta da habitação; c) Tamanho e locação de janelas e portas permitindo ventilação cruzada; d) Materiais de construção utilizados visando melhor desempenho térmico com baixo teor energético agregado; e) Tipo de estrutura do telhado e cobertura; f) Jardins, arbustos e árvores próximas às habitações para promover sombreamento e moderação do microclima.; Etapa 4.2 Roteiro de entrevista semiestruturada aplicada, especificamente, a um grupo focal constituído por 10 construtores vernaculares anciãos da Aldeia Indígena. Este grupo tem sido responsável por compartilhar o conhecimento referente às técnicas construtivas vernaculares com as novas gerações. A entrevista ocorreu entre os meses de maio e julho de 2018.

Quadro 1: O roteiro de entrevista contemplou 7 perguntas.

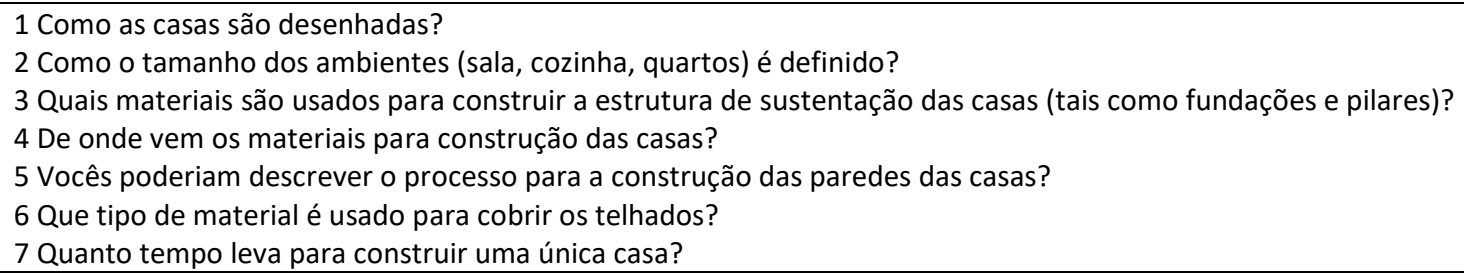

Para análise das entrevistas, procedeu-se primeiramente com a transcrição das repostas; por conseguinte, ideias centrais chave foram extraídas das transcrições e tabuladas em função de duas categoriais de análise textual: Categoria 1 Uso dos recursos naturais locais e Categoria 2 Senso de Comunidade.

\section{RESULTADOS}

\section{Estratégias arquitetônicas bioclimáticas intuitivas utilizadas no processo construtivo das habitações}

Esta sessão apresenta a análise da arquitetura das habitações da Aldeia Indígena Itapoã Tupinambá de Olivença, cujas informações foram registradas em diário de campo. As habitações foram analisadas considerando as estratégias arquitetônicas bioclimáticas, intuitivamente utilizadas pela Comunidade, no processo construtivo. A Tabela 2 apresenta a descrição dos aspectos observados de acordo com as variáveis de análise.

Tabela 2: Variáveis de análise referentes às estratégias arquitetônicas bioclimáticas e descrição dos aspectos observados nas habitações vernaculares da Aldeia Indígena Itapoã Tupinambá de Olivença.

\begin{tabular}{|l|l|l|}
\hline $\begin{array}{l}\text { Variáveis de análise referentes às } \\
\text { estratégias } \\
\text { bioclimáticas }\end{array}$ & $\begin{array}{l}\text { Descrição dos aspectos observados } \\
\begin{array}{l}\text { a) Posição da habitação em relação à } \\
\text { incidência solar e direção do vento }\end{array}\end{array}$ & $\begin{array}{l}\text { - A Aldeia foi construída no sentido longitudinal do sul para o norte e as } \\
\text { habitações estão organizadas ao longo de uma via de acesso principal. } \\
\text { ilustrativas }\end{array}$ \\
$\begin{array}{ll}\text { - As habitações recebem incidência solar do leste (direção do mar). } \\
\text { - A floresta tropical local protege as habitações da incidência solar do } \\
\text { oeste (sol da tarde). } \\
\text { - Direção dos ventos: do sudeste para o nordeste. }\end{array}$ \\
$\begin{array}{l}\text { - Design da planta das habitações apresenta formato retangular ou } \\
\text { quadrado. } \\
\text { - As habitações apresentam ambientes internos subdivididos em sala, } 2 \\
\text { cozinha e dois quartos. } \\
\text { - O banheiro está localizado do lado de fora das habitações. }\end{array}$ \\
\hline
\end{tabular}




\begin{tabular}{|c|c|c|}
\hline $\begin{array}{l}\text { c) Tamanho e locação de janelas e } \\
\text { portas permitindo ventilação cruzada }\end{array}$ & $\begin{array}{l}\text { - As janelas possuem cerca de } 60 \mathrm{~cm} \text { de largura } X 80 \mathrm{~cm} \text { de altura ou } 1,00 \mathrm{~m} \\
\text { de largura } X 1,00 \mathrm{~m} \text { de altura. As portas possuem } 70 \mathrm{~cm} \text { de largura } X \\
2,10 \mathrm{~m} \text { de altura. } \\
\text { - As portas e janelas não estão locadas de modo a permitir ventilação } \\
\text { cruzada. } \\
\text { - Tanto as portas quanto as janelas foram construídas com restos de } \\
\text { madeira e não possuem vidro. }\end{array}$ & Figura 3 \\
\hline $\begin{array}{l}\text { d) Materiais de construção utilizados } \\
\text { visando melhor desempenho térmico } \\
\text { com baixo teor energético agregado }\end{array}$ & $\begin{array}{l}\text { - A estrutura de sustentação (pilares) das habitações é feita de toras de } \\
\text { madeira com diâmetro variando entre } 8 \mathrm{~cm} \text { e } 10 \mathrm{~cm} \text {, diretamente } \\
\text { extraídas da Mata local. } \\
\text { - Não há estrutura de fundação. As toras de madeira são instaladas } \\
\text { diretamente no solo. } \\
\text { - O chão é feito de argamassa de cimento, água e areia (cimento } \\
\text { queimado). } \\
\text { - As paredes são feitas de tramas de toras rústicas de madeira, extraídas } \\
\text { da Floresta Tropical local, com diâmetros variando entre } 3 \mathrm{~cm} \text { e } 5 \mathrm{~cm} \text {, } \\
\text { amarradas com cipó. A trama é preenchida por uma argamassa } \\
\text { composta de argila, fibra natural e água. }\end{array}$ & Figura 4 \\
\hline $\begin{array}{l}\text { e) Tipo de estrutura do telhado e } \\
\text { cobertura }\end{array}$ & $\begin{array}{l}\text { - A estrutura do telhado é feita de toras rústicas de madeira, extraídas da } \\
\text { Mata local, com diâmetro variando de } 8 \mathrm{~cm} \text { a } 10 \mathrm{~cm} \text {. A cobertura do } \\
\text { telhado é feita de fibrocimento. } \\
\text { - A cobertura do telhado do Centro de Conferência da Aldeia Indígena é } \\
\text { feita de uma fibra natural (seca) denominada Maribu. }\end{array}$ & Figura 5 \\
\hline $\begin{array}{l}\text { f) Jardins, arbustos e árvores próximas } \\
\text { às habitações para promover } \\
\text { sombreamento e moderação do } \\
\text { microclima }\end{array}$ & $\begin{array}{l}\text { - Existem árvores de médio e grande porte ao redor das habitações, } \\
\text { assim como arbustos de médio porte e jardins. }\end{array}$ & Figura 6 \\
\hline
\end{tabular}

A figura 1 mostra a fachada frontal das habitações voltada para a estrada de acesso principal da Aldeia. A figura 2 mostra um desenho esquemático da planta baixa das habitações; o banheiro geralmente é construído do lado de fora da edificação e ao lado há uma fossa e um sumidouro. Além disso, o desenho mostra que a disposição das portas e janelas não permite a ventilação cruzada. A figura 3 apresenta a fotografia da fachada frontal de uma das habitações.

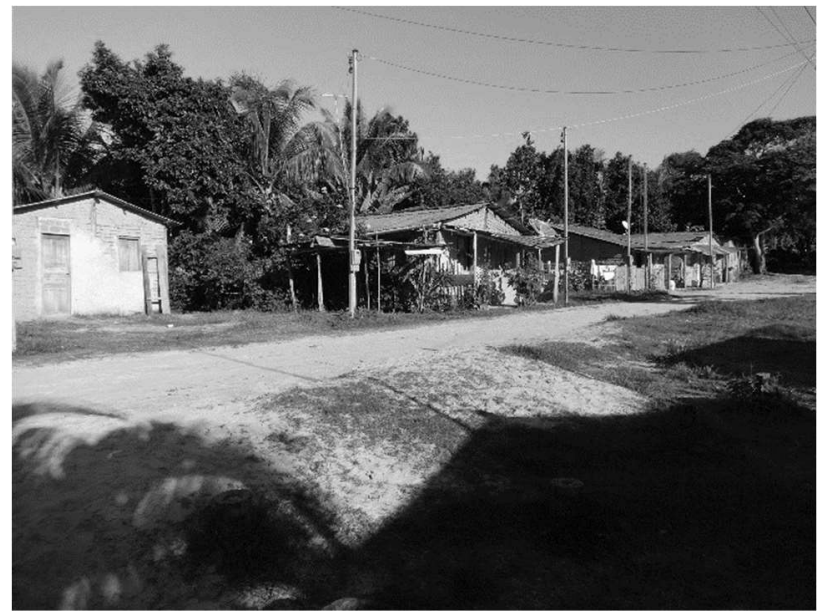

Figura 1: Fachada frontal das habitações em relação ao acesso principal da Aldeia.

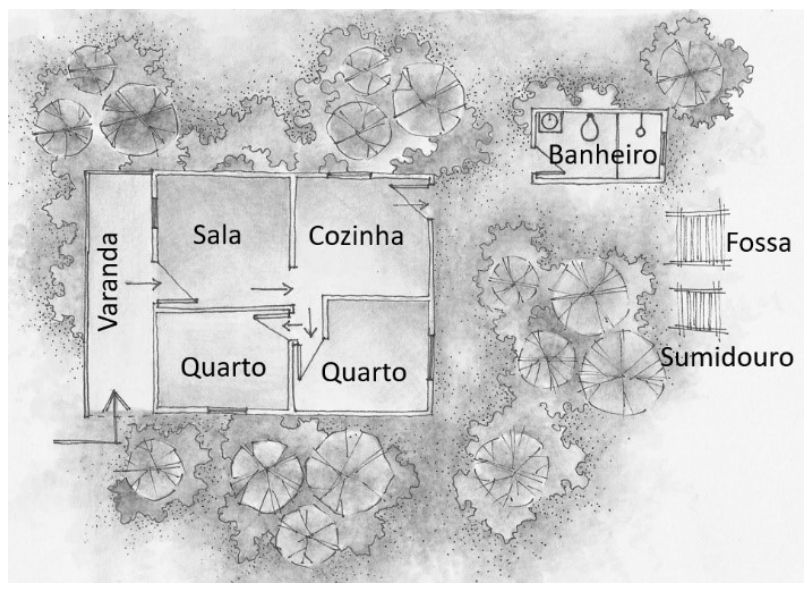

Figura 2: Desenho esquemático da planta baixa das habitações da Aldeia Indígena Itapoã Tupinambá de Olivença.

A figura 4 mostra parte da parede da habitação, feita de tramas de toras finas de madeira rústica e coberta pela argamassa de argila, areia, fibra natural e água. O Centro de Conferência da Aldeia é usado para rituais indígenas e reuniões comunitárias. A figura 5 mostra a estrutura do telhado do referido Centro coberta pelo Maribu (Becquerelia Cymosa), que é uma fibra natural que cresce às margens do rio que corre pelo interior da Mata local. Esse tipo de cobertura proporciona um melhor conforto térmico interno à edificação. 
O processo de retirada do Maribu e a preparação das camadas da fibra para cobrir o telhado são realizados pelas mulheres. A cobertura da estrutura de madeira do telhado é feita pelos homens. A Figura 6 mostra os jardins e as árvores ao redor das habitações. As árvores permitem sombreamento intenso e contribuem para o conforto ambiental interno.

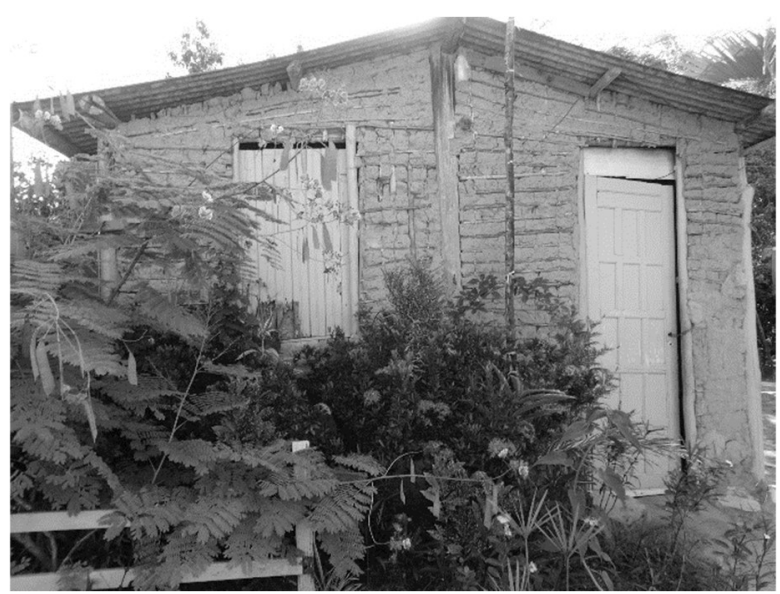

Figura 3: Fachada frontal de uma das habitações da Aldeia Indígena Itapoã Tupinambá de Olivença.

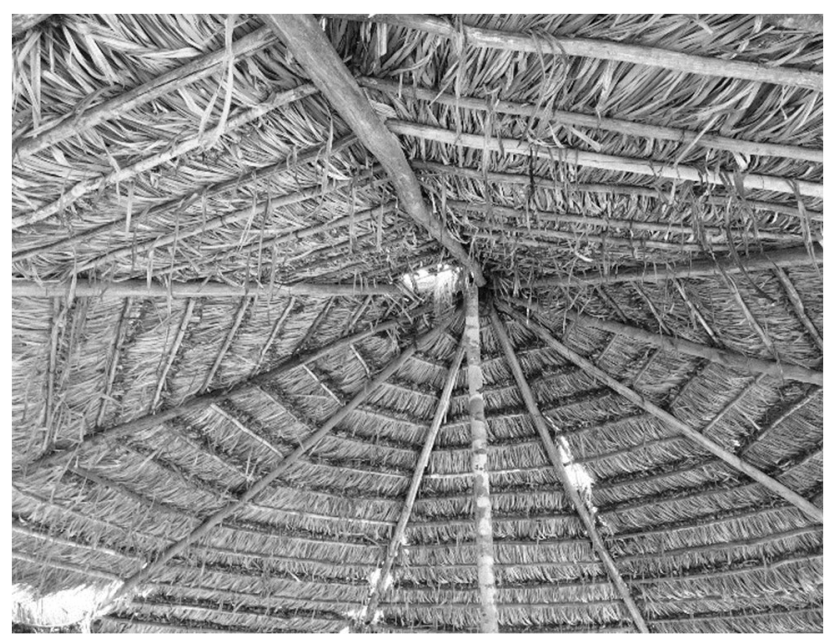

Figura 5: Cobertura da estrutura do telhado do Centro de Conferência da Aldeia Indígena Itapoã Tupinambá de Olivença.

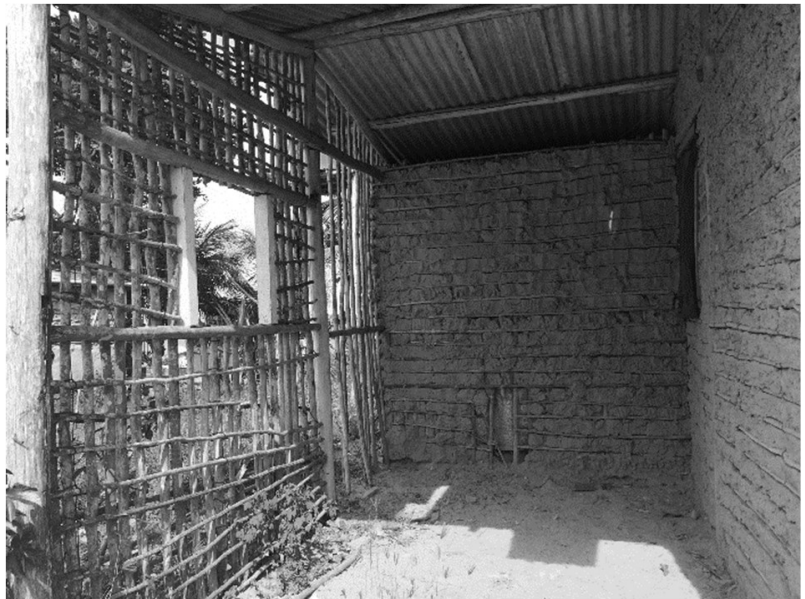

Figura 4: Parede de uma das habitações da Aldeia Indígena Itapoã Tupinambá de Olivença.

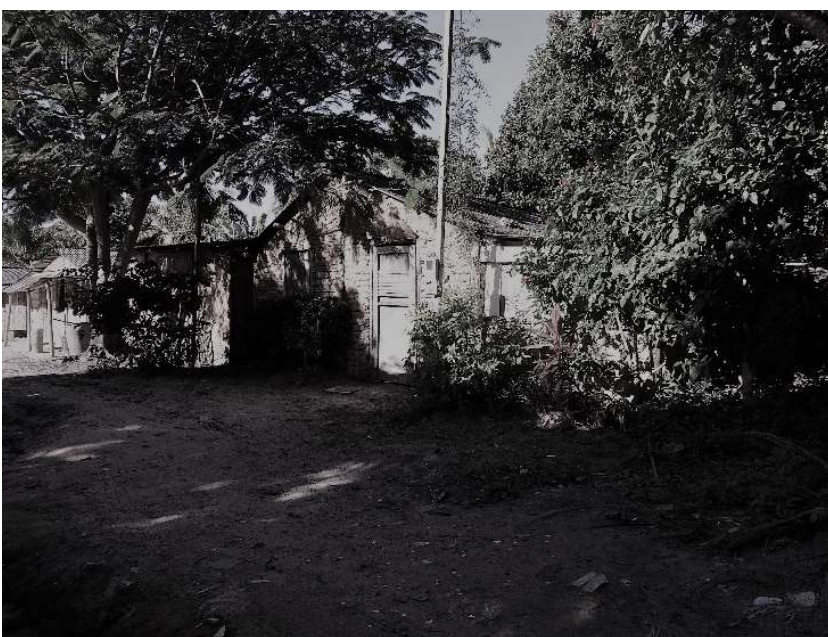

Figura 6: Jardins e as árvores ao redor das habitações da Aldeia Indígena Itapoã Tupinambá de Olivença.

\section{A relação meio ambiente e comunidade}

Esta sessão apresenta o quadro analítico (Tabela 3) contendo as questões do roteiro de entrevista (aplicado ao grupo focal constituído por construtores anciãos da Aldeia), as ideias centrais chave extraídas das respostas transcritas do referido roteiro, e a correlação dessas respostas à duas categorias de análise textual: $1^{\circ}$ Uso dos recursos naturais locais e $2^{\circ}$ Senso de Comunidade.

Tabela 3: Questões do roteiro de entrevista semiestruturada/ categoriais de análise textual/ ideias-chave extraídas das respostas transcritas.

\begin{tabular}{|l|l|l|}
\hline $\begin{array}{l}\text { Questões do roteiro de entrevista } \\
\text { semiestruturada }\end{array}$ & Categorias de análise textual/ ideias centrais chaves* \\
\cline { 2 - 3 } 1 Como as casas são desenhadas? & $1^{\circ}$ Uso dos recursos naturais locais & $2^{\circ}$ Sendo de Comunidade \\
\hline $\begin{array}{l}\text { 2 Como o tamanho dos ambientes } \\
\text { (sala, cożnos são de Pau-a-Pique e não muito }\end{array}$ & $\begin{array}{l}\text { Não há desenho prévio da habitação feito por algum } \\
\text { grandes por causa da quantidade de madeira que } \\
\text { profissional da área de construção civil. } \\
\text { precisa ser extraída da Mata local e da }\end{array}$ & \\
\hline
\end{tabular}




\begin{tabular}{|c|c|c|}
\hline & $\begin{array}{l}\text { quantidade de argila para fechamento das } \\
\text { paredes. } \\
\text { A construção das habitações é feita uma ao lado } \\
\text { da outra para proteção contra as tempestades e } \\
\text { ao longo da via principal de acesso à Aldeia/ } \\
\text { Construímos assim desde que chegamos à } \\
\text { Reserva. }\end{array}$ & $\begin{array}{l}\text { A habitação é planejada de forma coletiva pelo grupo } \\
\text { de anciãos da Aldeia Indígena considerando o } \\
\text { tamanho da família a qual se destina. }\end{array}$ \\
\hline $\begin{array}{l}3 \text { Quais materiais são usados para } \\
\text { construir a estrutura de sustentação } \\
\text { das casas (tais como fundações e } \\
\text { pilares)? }\end{array}$ & \multirow{2}{*}{$\begin{array}{l}\text { Extraímos da Mata local apenas a quantidade de } \\
\text { madeira necessária para construir a habitação. } \\
\text { Não há necessidade de derrubar árvores. } \\
\text { Não há estrutura de fundação. Nós colocamos as } \\
\text { toras de madeira diretamente no solo. }\end{array}$} & \multirow{2}{*}{$\begin{array}{l}\text { Toda a comunidade é envolvida no processo/ Nós } \\
\text { iniciamos a extração de toras e galhos de madeira, da } \\
\text { Mata Local, no início da manhã. Mas não terminamos } \\
\text { a extração num só dia, pois precisamos esperar a lua } \\
\text { nova. }\end{array}$} \\
\hline $\begin{array}{l}4 \text { De onde vem os materiais para } \\
\text { construção das casas? }\end{array}$ & & \\
\hline $\begin{array}{l}5 \text { Vocês poderiam descrever o } \\
\text { processo para a construção das } \\
\text { paredes das casas? }\end{array}$ & $\begin{array}{l}\text { A argila vem de uma área muito próxima da } \\
\text { Aldeia, mas distante do rio da Mata local. }\end{array}$ & $\begin{array}{l}\text { Toda a comunidade é envolvida no processo/ Chama- } \\
\text { se 'barrear' / O processo envolve cântico indígenas e } \\
\text { um banquete no final da construção da habitação. }\end{array}$ \\
\hline $\begin{array}{l}6 \text { Que tipo de material é usado para } \\
\text { cobrir os telhados? }\end{array}$ & $\begin{array}{l}\text { Não é possível usar Maribu para cobertura de } \\
\text { habitações já que não há quantidade suficiente } \\
\text { deste tipo de planta na Aldeia. } \\
\text { Usamos telhas de fibrocimento. Sabemos que } \\
\text { aquece os quartos, mas a telha de fibrocimento } \\
\text { requer uma quantidade menor de madeira para } \\
\text { a estrutura do telhado. }\end{array}$ & $\begin{array}{l}\text { A cobertura do telhado é também um trabalho que } \\
\text { envolve toda comunidade. }\end{array}$ \\
\hline $\begin{array}{l}7 \text { Quanto tempo leva para construir } \\
\text { uma única casa? }\end{array}$ & $\begin{array}{l}\text { O tempo de construção da habitação demora } \\
\text { cerca de } 60 \text { dias, variando de acordo com as } \\
\text { condições climáticas da região. }\end{array}$ & $\begin{array}{l}\text { A comunidade envolve-se durante todo o período de } \\
\text { construção da habitação. }\end{array}$ \\
\hline
\end{tabular}

\section{DISCUSSÃO}

As observações registradas em diário de campo e sintetizadas na Tabela 2 (apresentada na seção anterior), permitiram concluir que a construção das primeiras habitações ocorreu em uma pequena clareira na Floresta Tropical local, mais próxima do mar e da Rodovia que liga o município de llhéus ao município de Una. Habitações subsequentes foram construídas lado a lado no sentido do sul para o norte, formando uma via de acesso principal central. As habitações estão dispostas para aproveitar a incidência solar matinal e a brisa do mar. Fachadas de frente para o oeste são sombreadas pela Mata local.

As habitações foram construídas lado a lado, distando entre si cerca de $1,00 \mathrm{~m}$ a $1,50 \mathrm{~m}$. A proximidade entre elas permite melhor proteção contra as chuvas torrenciais e ventos fortes que impactam a Aldeia no sentido sudeste - noroeste. A necessidade de proteção contra a intempérie excessiva ocorre porque a estrutura das habitações, construídas em Pau-a-Pique, é feita diretamente sobre o solo sem $r$ estrutura de fundação e laje de piso. A falta de estrutura de sustentação em relação ao solo faz com que a base das habitações se deteriore rapidamente e as paredes se desmanchem.

Cabe pontuar que a argamassa feita de argila, areia, água e fibras para cobrir a trama de madeira do Pau - a - Pique, assim como outros elementos de vedação para paredes compostos por argila possibilitam desempenho térmico com baixo conteúdo energético agregado (GALDINO, 2010; GOODHEW et al., 2005), entretanto, a localização das janelas e portas nas habitações da Aldeia Indígena estudada não permite ventilação cruzada que, aliada à cobertura em fibrocimento, inviabiliza o conforto térmico interno. Na maior parte do dia, as habitações são muito quentes. A moderação do microclima é possível devido à grande quantidade de árvores e jardins ao redor das habitações e proximidade com a Mata local.

Conforme consta na Tabela 3 (apresentada na seção anterior), a relação meio ambiente e Comunidade tem sido caracterizada pela atividade extrativista para subsistência. Ou seja, retira-se da Mata 
local apenas o necessário para a construção das habitações e necessidades alimentícias da Comunidade. Todo processo é coordenado pelo grupo de anciãos da Aldeia Indígena. É esse grupo que especifica, de acordo com o tamanho da família, o número de cômodos da habitação e, em seguida, calcula a quantidade de toras e galhos das árvores que deverão ser extraídos da Mata local para montar a estrutura da edificação. Entre as espécies arbóreas utilizadas na construção da habitação, o grupo de anciãos destaca: Biriba (Eschweilera ovata (Cambess.) Mart. Ex Miers); Aderno (Emmotum affine Miers); Inhaíba (Lecythis lurida (Miers) S. A. Mori) e Musserengue (Vochisia lucida Klotzsch ex M.R. Schomb). Estas são espécies nativas da Mata Atlântica localizada no Litoral do Estado da Bahia (NUNES et al., 2017).

Conforme explicou o grupo de anciãos, a madeira não pode ser removida da Mata local a qualquer momento. A extração deve ocorrer durante a lua nova para evitar que seja posteriormente consumida por cupins. A confecção da estrutura e tramas de madeira é que conforma os cômodos da habitação e o formato do telhado. O processo de 'barrear' (vedação com a argamassa de argila, areia, água e fibras naturais) é iniciado logo após a conclusão da estrutura. A extração da argila é feita dentro da Reserva, próxima à Aldeia, mas distante do rio que corre pelo interior da Mata local. A conclusão de uma habitação leva cerca de 45 a 60 dias a depender das condições climáticas da região, pois se estiver chovendo não é possível 'barrear' a habitação.

Para cobertura das habitações tem sido usada a telha em fibrocimento que é inadequada para viabilizar o conforto interno dos ambientes. O grupo de anciãos explicou que é possível usar a piaçava como material alternativo, mas a Aldeia não produz essa fibra havendo necessidade de adquiri-la por meio da compra, e a fibra não possui preço acessível para a Comunidade. Outra alternativa seria a utilização do Maribu, porém, o grupo de anciões alerta que um número maior de plantas seria necessário para cobrir os telhados das 50 habitações da Aldeia e não há quantidade suficiente na Mata local. Dessa forma, o Maribu tem sido usado apenas para cobertura do Centro de Conferências da Aldeia. Depois que o Maribu é extraído, a Comunidade aguarda o próximo ciclo de crescimento da planta.

Outro aspecto verificado, foi a presença de pilhas de tijolos cerâmicos próximas a algumas habitações. $O$ grupo de anciãos informou que se trata da substituição de algumas paredes em Pau-a-Pique pelo material convencional. Isso vem ocorrendo porque o Pau-a-Pique apresenta pouca durabilidade às intempéries e para a reconstrução das paredes é necessário seguir o ritual de espera pela lua nova para retirada da madeira da Mata. Por esse motivo os moradores de algumas habitações vêm optando pela aquisição e uso de materiais construtivos convencionais. Isso corrobora a hipótese da Pesquisa; entretanto, existem tecnologias de Bioconstrução que melhoram o desempenho dos materiais utilizados e que podem ser ensinados à Comunidade de modo a preservar o processo construtivo coletivo vernacular.

No que tange ao processo coletivo de construção das habitações, fica claro que o conhecimento referente à tecnologia construtiva é passado para os mais jovens pelos construtores vernaculares anciãos da Aldeia e que toda Comunidade precisa participar do processo. O processo de construção coletiva é permeado por rituais que fortalecem os laços sociais dentro da Comunidade, seja durante a extração da madeira para 
a confecção da estrutura da habitação, seja durante o processo de 'barrear'. As etapas de construção da habitação envolvem rituais de celebração através da música e do compartilhamento de alimentos.

Num contexto iniciado em 2001 quando o povo Tupinambá de Olivença reconheceu sua identidade indígena, mesmo após "um longo processo de submissão colonial, expropriação territorial e invisibilidade étnica" (ROCHA, 2014), a construção coletiva da habitação significa uma constante demarcação física do espaço da Aldeia - 'esse é nosso lugar' - e um desejo de vida próspera para a família que lá irá residir.

\section{CONCLUSÕES}

Este artigo apresentou a análise das habitações vernaculares construídas em Comunidades Tradicionais localizadas entre os municípios de Itacaré e Una, Litoral Sul da Bahia, Brasil. O mapeamento identificou o Pau-a-Pique como tipologia construtiva predominante na área de abrangência da Pesquisa. Essa tipologia construtiva se enquadra na classificação conhecida como Arquitetura Vernacular Praieira.

Entre as Comunidades Tradicionais visitadas durante a Pesquisa, a maior quantidade de habitações construídas em Pau-a-Pique, envolvendo o processo de construção coletiva, foi encontrada na Aldeia Indígena Itapoã Tupinambá, localizada no Distrito de Olivença no município de Ilhéus, Bahia. Portanto, a coleta das informações foi realizada nesta Aldeia.

Os dados coletados objetivaram descrever o processo construtivo coletivo das habitações considerando as estratégias arquitetônicas bioclimáticas intuitivas utilizadas no processo e a relação meio ambiente e Comunidade. A descrição do processo construtivo das habitações possibilitou compreender sua importância para a sustentabilidade ambiental local e a necessidade não só do registro, mas também de sua preservação.

Os resultados permitiram concluir que o sentido de Comunidade e compromisso com a preservação do Meio Ambiente e cultura local perpassa por todo processo de planejamento e construção das habitações. Esse processo envolve solidariedade comunitária, rituais de celebração, compartilhamento de conhecimento através das gerações e o estabelecimento de uma conexão contínua com a Natureza.

\section{REFERÊNCIAS}

ALVES, S.. The Sustainable Heritage of Vernacular Architecture: The Historic Center of Oporto. Procedia Environmental Sciences, v.38, p.187-195, 2017. DOI: http://doi.org/10.1016/i.proenv.2017.03.105

ANDRADE, F. C. D.. Uma poética da técnica: a produção da arquitetura vernacular no Brasil. Tese (Doutorado em História) - Universidade Estadual de Campinas, Instituto de Filosofia e Ciências Humanas, Campinas, 2016.

ASQUITH, L.; VELLINGA, M.. Vernacular Architecture in the Twenty-first century. London and New York: Taylor \& Francis Group, CRC Press, 2005.

BECALLI, M.; GERMANÀ, M. L.; MELLUSO, V.; GALATIOTO, A. Vernacular and bioclimatic architecture and indoor thermal com fort implications in hot-humid climates: An overview.
Renewable and Sustainable Energy Reviews, v.82, p.17261736, 2018. DOI: https://doi.org/10.1016/j.rser.2017.06.062

BRASIL. Decreto n. 6.040: Institui a Política Nacional de Desenvolvimento Sustentável dos Povos e Comunidades Tradicionais. Brasília: Casa Civil, 2007.

CHANDEL, S. S.; SHARMA, V.; MARWAH, B. M.. Review of energy efficient features in vernacular architecture for improving indoor thermal comfort conditions. Renewable and Sustainable Energy Reviews, v. 65, p. 459-477, 2016. DOI: http://dx.doi.org/10.1016/j.rser.2016.07.038.

CNS. Conselho Nacional de Saúde. Resolução № 196: diretrizes e normas regulamentadoras de pesquisas envolvendo seres humanos. Brasília: Ministério da Saúde, 1996. 
CNS. Conselho Nacional de Saúde. Resolução n. 304: regulamentação complementar da Resolução CNS no 196/96 (Diretrizes e Normas Regulamentadoras de Pesquisas Envolvendo Seres Humanos), atribuição da CONEP conforme item VIII.4.d da mesma Resolução, no que diz respeito à área temática especial 'populações indígenas'. Brasília: Ministério da Saúde, 2000.

CNS. Conselho Nacional de Saúde. Resolução n. 510: dispõe sobre as normas aplicáveis a pesquisas em Ciências Humanas e Sociais cujos procedimentos metodológicos envolvam a utilização de dados diretamente obtidos com os participantes ou de informações identificáveis ou que possam acarretar riscos maiores do que os existentes na vida cotidiana. Brasília: Ministério da Saúde, 2016.

CORBELLA, O.; CORNER, V.. Manual de Arquitetura Bioclimática Tropical para redução do consumo energético. Rio de Janeiro: Revan, 2011.

$\mathrm{COCH}, \mathrm{H}$.. Bioclimatism in vernacular architecture.

Renewable and Sustainable Energy Reviews, v.2, p.67-87, 1998.

CORREA, M., CARLOS, G; ROCHA, S.. Vernacular Heritage and Earthen Architecture: contributions for sustainable development. Boca Raton: Taylor \& Francis Group, CRC Press, 2014

DONOVAN, K.; GKARTZIOS, M.. Architecture and rural planning: Claiming the Vernacular. Land Use Policy, v.41, p.334-343, 2014. DOI: http://dx.doi.org/10.1016/j.landusepol.2014.06.013

DURAN, S. C.. Architecture and Energy Efficiency. Barcelona: FKG, 2011.

GALDINO, C.. Casas de mãos e barro: a arquitetura caiçara de São Sebastião. Cadernos do CEOM etnicidades, v.23, n.32, p.77-97, 2010.

GOODHEW, S.; GRIFFITHS, R.. Sustainable earth walls to meet the building Regulations. Energy and Buildings, v.37, p.451-459, 2005. DOI: http://doi.org/10.1016/j.enbuild.2004.08.005

GUY, S.; FARMER, G.. Reinterpreting Sustainable Architecture: the place of Technology. Journal of Architecture Education, v.54, n.3, p.140-148, 2001.

HAMARD, E.; CAZACLIU, B.; RAZAKAMANANTSOA, A.; MOREL, J.-C.. Cob, a vernacular earth construction process in the context of modern sustainable building. Building and Environment, v.106, p.103-119, 2016. DOI: https://doi.org/10.1016/j.buildenv.2016.06.009

HĂRMĂNESCU, M.; ENACHE, C.. Vernacular and Technology. InBetween. Procedia Environmental Sciences, v.32, p.412419, 2016.

KIBERT, C. J.. Sustainable Construction: Green Building Design and Delivery. New Jersey: John Wiley \& Sons Inc, 2013.

LIMA JUNIOR, G.. Arquitetura Vernacular Praieira. Recife: Animarte Consultoria, 2007.
MANZANO-AGUGLIARO, F.; MONTOYA, F. G.; SABIO-

ORTEGA, A.. Review of bioclimatic architecture strategies for achieving thermal comfort. Renewable and Sustainable Energy Reviews, v.49, p.737-743, 2015. DOI: http://dx.doi.org/10.1016/j.rser.2015.04.095

MENDONÇA, F.; DANNI-OLIVEIRA, I. M.. Climatologia: noções básicas e climas do Brasil. São Paulo: Oficina de Textos, 2007.

MOREL, J. C.; MESBAH, A.; OGGERO, M.; WALKER, P.. Building houses with local materials: means to drastically reduce the environmental impact of construction. Building and Environment, v.36, p.1119-1126, 2001.

NUNES, J. M. C.; MATOS, M. R. B.. Litoral Norte da Bahia: caracterização ambiental, biodiversidade e conservação. Salvador: EDUFBA, 2017.

OLIVER, P.. Built to meet needs: cultural issues in Vernacular Architecture. Oxford: Elsevier LTDA, 2006.

PHILOKYPROU, M.; MICHAEL, A.. Evaluation of thcLle environmetal features of Vernacular Achitecture. A case study in Cyprus. In: EUROMED: PROGRESS IN CULTURAL HERITAGE PRESERVATION. Anais. 2012. p.349-354.

PHILOKYPROU, M.; MICHAEL, A.; MALAKTOU, E.; SAVVIDES, A.. Environmentally responsive design in Eastern Mediterranean. The case of vernacular architecture in the coastal, lowland and mountainous regions of Cyprus. Building and Environment, v.111, p.91-109, 2017. DOI: https://doi.org/10.1016/j.buildenv.2016.10.010

PLEVOETS, B.; SOWIŃSKA-HEIM, J.. Community initiatives as a catalyst for regeneration of heritage sites: Vernacular transformation and its influence on the formal adaptive reuse practice. Cities, v.78, p.128-139, 2018. DOI: https://doi.org/10.1016/j.cities.2018.02.007

PREVITALI, J. M.; ZHAI, Z. J.. A taxonomy of vernacular architecture: An addendum to the Ancient vernacular architecture: Characteristics categorization and energy performance evaluation (Zhai and Previtali, 2010). Energy and Buildings, v.110, p.71-78, 2016. DOI: https://doi.org/10.1016/i.enbuild.2015.10.015

ROCHA, C. C.. Bora vê quem pode mais: Uma etnografia sobre o fazer política entre os Tupinambá de Olivença (Ilhéus, Bahia). Tese (Doutorado em Antropologia Social) Universidade Federal de Santa Catarina, Florianópolis, 2014.

SAMPAIO, R. F.; MANCINI, M. C.. Estudos de revisão sistemática: um guia para síntese criteriosa da evidência científica. Revista Brasileira de Fisioterapia, v.11, n.1, p.8389, 2007.

SANTOS, S. C.; COSTA, S. K.. Vernacular or Popular Brazilian Architecture: approaches, building aspects and cultural identity. Cadernos de Arquitetura e Urbanismo, v.24, n.35, p.218-258, 2017. DOI: https://doi.org/10.5752/P.2316$\underline{1752.2017 v 24 n 35 p 218}$

SANTOS, A. A. P.; FRANÇA, S.; Caracterização espaçotemporal do regime pluviométrico da Região Sul da Bahia. In: SEMINÁRIO DE PÓS-GRADUAÇÃO EM GEOGRAFIA DA UNESP: 'TEORIAS E METODOLOGIAS DA GEOGRAFIA: 
TENDÊNCIAS E PERSPECTIVAS', 9. Anais. Rio Claro, 2009, p.14-33.

WEBER, W.; YANNAS, S.. Lessons from Vernacular

Architecture. London and New York: Taylor \& Francis Group, Routledge, 2014.
WEIMER, G.. Arquitetura Popular Brasileira. São Paulo: Martins Fontes, 2005.

ZHAI, Z. J.; PREVITALI, J. M.. Ancient vernacular architecture: characteristics categorization and energy performance evaluation. Energy and Buildings, v.42, p.357-365, 2010. DOI: http://doi.org/10.1016/i.enbuild.2009.10.002

A CBPC - Companhia Brasileira de Produção Científica (CNPJ: 11.221.422/0001-03) detém os direitos materiais desta publicação. Os direitos referem-se à publicação do trabalho em qualquer parte do mundo, incluindo os direitos às renovações, expansões e disseminações da contribuição, bem como outros direitos subsidiários. Todos os trabalhos publicados eletronicamente poderão posteriormente ser publicados em coletâneas impressas sob coordenação da Sustenere Publishing, da Companhia Brasileira de Produção Científica e seus parceiros autorizados. Os (as) autores (as) preservam os direitos autorais, mas não têm permissão para a publicação da contribuição em outro meio, impresso ou digital, em português ou em tradução. 